\title{
POSITIVE SOLUTIONS FOR A FOURTH ORDER DIFFERENTIAL INCLUSION BASED ON THE EULER-BERNOULLI EQUATION FOR A CANTILEVER BEAM
}

\author{
JOHN S. SPRAKER
}

Abstract. An existence result for positive solutions to a fourth order differential inclusion with boundary values is given. This is accomplished by using a fixed point theorem on cones for multivalued maps, $L^{1}$ selections and a generalization of the Ascoli theorem. The inclusion allows the function and its first three derivatives to be on the right-hand side. The proof involves a Green's function and a positive eigenvalue of a particular operator. An example is provided.

Mathematics subject classification (2010): 34B18, 34A34, 34A36, 34A60, 34B15, 47H10.

Keywords and phrases: Existence of solutions, fourth order differential inclusion, fixed point, boundary value problem, Ascoli theorem.

\section{REFERENCES}

[1] R. P. Agarwal, D. O'Regan, Set valued mappings with applications in nonlinear analysis, Taylor \& Francis, 2002.

[2] M. Aitalioubrahim, On fourth-order boundary-value problems, Acta Univ. Palacki. Olomuc., Fac. Rer. Nat. Mathematica, 49 (2010), 5-16.

[3] A. Arara, M. Benchohra, S. K. Ntouyas, A. OuAhab, Existence results for boundary value problems for fourth-order differential inclusions with nonconvex valued right hand side, Arch. Math. (Brno), 40 (2004), 219-227.

[4] J. P. Aubin, A. Cellina, Differential Inclusions, Springer, 1984.

[5] J. P. Aubin, H. FrankowsKa, Set-valued analysis, Birkhäuser, 1990.

[6] D. C. BILES, J. S. SPRAKER, Existence of positive solutions for a fourth order differential inclusion, Differ. Equ. Appl., 4(2012), 539-546.

[7] A. CERneA, Filippov lemma for a certain differential inclusion of fourth-order, Bull. Math. Soc. Sci. Math. Roum., Nouv. Ser. 56 (104), No. 2, (2013), 181-189.

[8] P. M. FitzPATRICK AND W. V. PETRYSHYn, Fixed point theorems and fixed point index for multivalued mappings in cones, J. London math. Soc. (2), 12 (1975), 75-85.

[9] B. M. GERHAT, Krein-Rutman theorem on the spectrum of compact positive operators on ordered Banach spaces, Diplomarbeit, Vienna University of Technology, 2016.

[10] Y. LI, Existence of positive solutions for the cantilever beam equations with fully nonlinear terms, Nonlinear Anal., Real World Appl., 27(2016), 221-237.

[11] R. Y. MA, Multiple positive solutions for a semipositone fourth-order boundary value problem, Hiroshima Math. J., 33 (2003), 217-227.

[12] R. Y. MA, J. ZHANG, M. FU, The method of lower and upper solutions for fourth-order two-point boundary value problems, J. Math. Anal. Appl., 215 (1997), 415-422.

[13] T. PRUSzKO, Topological degree methods in multivalued boundary value problems, J. Nonlinear Anal., 5 (1981), 953-973.

[14] D. Repovs, P. V. Semenov, Continuous selections of multivalued mappings, Springer, 1998.

[15] J. S. SPRAKer, Positive solutions for a fourth order differential inclusion with boundary values, Differ. Equ. Appl., 8 (2016), No. 1, 21-31. 
[16] M. SvEC, Periodic boundary value problem for fourth order differential inclusions, Arch. Math. (Brno), 33 (1997), 167-171.

[17] B. YANG, Positive solutions for a fourth order boundary value problem, Electronic J. Qual. Theory of Differ. Equ., 3 (2005), 1-17.

[18] Y. Zou, On the existence of positive solutions for a fourth-order boundary value problem, J. Funct. Spaces, (2017), Art. ID 4946198, 5 pp. 